\title{
Botswana's Ipelegeng Programme Design and Implementation: Reduction or Perpetuation/Entrenchment of Poverty?
}

\author{
Keitseope Nthomang ${ }^{1}$ \\ ${ }^{1}$ Faculty of Social Sciences, University of Botswana, Gaborone, Botswana \\ Correspondence: Keitseope Nthomang, Faculty of Social Sciences, University of Botswana, PB UB 0705, \\ Gaborone, Botswana.
}

Received: June 19, 2018

Accepted: July 24, 2018

Online Published: August 13, 2018

doi:10.20849/ajsss.v3i3.445

URL: https://doi.org/10.20849/ajsss.v3i3.445

\begin{abstract}
Botswana launched a Public Works Programme (PWP) - commonly known as Ipelegeng (IP) in 2008 as one, among a myriad of initiatives meant to reduce poverty for sustainable development in marginalized contexts. Research shows that well designed and properly implemented (PWPs) have potential to reduce poverty among the poor by creating the much needed employment opportunities and other forms of sustainable livelihood. This paper assesses the contribution of Ipelegeng towards poverty reduction in Botswana. A nationwide review of Ipelegeng was conducted in 2012. In-depth interviews and focus group discussions (FGDs) were conducted at 23 research sites followed by a detailed analysis of data collected. Evidence based on both empirical and documentary analysis suggests that although Ipelegeng has made some contribution to poverty reduction, its successes are far outweighed by its failures. Poor programme designs and flawed implementation has been blamed for Ipelegeng failure to deliver on set objectives. This paper concludes by asserting the need for the development of robust Ipelegeng designs and implementation tools that will ensure the realisation of sustained poverty reduction outcomes.
\end{abstract}

Keywords: poverty reduction, Ipelegeng, beneficiaries, contribution, effectiveness and Botswana

\section{Introduction}

Since independence, the Botswana Government (GoB) has initiated development programmes geared towards reduction of poverty, specifically singling out the poor as a target group. The concept of Ipelegeng, which literally means self-reliance, is not new to Botswana. It is has been part of Botswana development traditions since the incipience of time. Institutionally, it was emphasized as one of Botswana's development principles since independence with a view to promote inclusive growth and development. The Ipelegeng initiative acknowledged that, relative to other population groups, the poor were underdeveloped, marginalized and therefore needed special attention in respect of development assistance. To this end, the IP programme sought to respond directly to the problems the poor people in Botswana face as a disadvantaged group with a view to improve their socio-economic wellbeing, livelihoods and quality of life. IP has become a popular Government programme co-ordinated by the Ministry of Local Government and Rural Development. The broad goal of IP is to reduce poverty through employment creation. Other aspects of the IP programme include; engaging beneficiaries in income generating activities, community leadership and active participation in local development projects. Realization of IP aims requires engaging Batswana in community development projects which include road maintenance, slashing of grass, unblocking storm water drainage and promoting income-generating activities such as catering. Ipelegeng is premised on the spirit of self-help, self-reliance and people centred development, the values which have been an integral part of Botswana society's culture and traditions since from time immemorial.

The overall objective of this paper is to assess the contribution of IP towards poverty reduction in Botswana. Specifically, the paper draws on qualitative research evidence to identify factors that have hindered and undermined the design and effective implementation of the IP programme. Recommendations are made with a view to improving IP effectiveness. Most importantly, the paper seeks to answer the following questions:

1. What is IP and what was it meant to achieve? What is it doing currently and what are the results? Has IP succeeded in meeting its objectives? If not, why and what have been the challenges? 
2. Does IP design conform to "best practice" principles in PWPs and has the actual implementation of IP followed these principles?

3. How can IP be made more effective so that it can achieve its objectives? That is, can IP provide solutions to the challenges facing the poor in Botswana?

The paper is structured as follows. Following the introduction, section two provides a brief literature review and conceptual framework underpinning arguments advanced in this paper. Section three is the study methodology. This is followed by section four which report the study findings, essentially drawing from empirical data. It discusses the design, objectives and implementation successes and challenges of the Ipelegeng programme. Section five is the discussion and analysis of critical issues emerging from the IP data. Finally, section six provides concluding remarks.

\section{Public Works Programmes (PWPs): A Brief Overview of the Literature}

Over the past few decades, numerous studies have been conducted around the world on the efficacy of public works programmes (Teklu, 1995; Teklu \& Asefa, 1999; Subbarao, 1997; 1999; 2003; Gobotswang, 2004; Samson, van Niekerk \& Mac Quene, 2006; Lal R., Miller S., Lieuw-Kie-Song M., and Kostzer D. 2010). Much debate has focused on developing effective designs and implementation tools for such programmes with a view to creating employment opportunities and reducing poverty (Phillips; 2004; Subbarao; 2003). The strategy remains a driving force today (UNDP, 2002; Vision 2036). Historically, India was the first Asian country in 1965 to experiment with PWPs. Subbarao (2003:20) asserted that, India's relative success in its PWPs can be attributed to the design of such programmes. India's PWPs are state funded and the focus is on the wage rate. They are designed such that they operate throughout the year. According to McCord (2000) the advantage of the medium to long-term PWP intervention initiatives is that they enabled consumption smoothing and accumulation in the form of assets and savings, given sustained employment opportunities. Unlike in India, PWPs in Africa have mainly been donor funded. Since donor funds are typically short term and run for a few months or years and then dry up, this has undermined most African countries' opportunity to build their capacity to manage the public works programmes. Moreover, donor funded programmes normally come with technical staff, an aspect that has further denied recipients the chance to develop their own capacity to design and manage such programmes (del Nnino, Subbarao, Millazo, 2009).

Botswana's experiment with PWPs can be traced back to drought relief programmes initiatives of the 1960s. However, in the 1990s these initiatives metamorphosed to incorporate poverty reduction through employment creation. With the new emphasis being on employment creation, the drought relief programme was re-named the Labour Intensive Public Works programme, and this was fully funded by the government. The new Labour Intensive Public Works Programme mandated all Government departments to use the labour intensive approach in all public works activities (Ministry of Local Government, 1996). In 2008, when President Lt. General Dr. Ian Khama Seretse Khama took office, the Labour-Intensive Public Works programme changed its name and purpose on a permanent basis to become Ipelegeng - with greater focus on employment creation and poverty reduction.

PWPs in Botswana have been evaluated or reviewed several times. Overall, the evaluations acknowledged that some achievements had been made, particularly in terms of the numbers of poor people that were engaged, and that no one across the country had died from hunger or malnutrition. This notwithstanding, a number of weaknesses in respect of delivery on programme objectives of reducing poverty, employment creation, improving incomes and the general quality of life were identified. These included, among others; (i) lack of implementation capacity and high material and supervisory costs relative to the benefits accruing to the participants; (iii) lack of supervision and control which had led to poor workmanship in some projects; (iv) political pressure compromising on quality of projects; and (v) PWPs tendency of creating a dependency syndrome and the creation of 'artificial' (subsidized) jobs at the expense of productivity and efficiency (Ministry of Local Government, 1996). Furthermore, the reviews found that the creation of many jobs under the programme not only lead to low productivity but also resulted in low quality infrastructure being provided in the rural communities. Similar challenges were also identified during the Review of the current Ipelegeng Programme by the Botswana Institute for Development Policy Analysis in 2012 (BIDPA \& UNICEF, 2012).

\subsection{Conceptual Framework}

For purposes of this paper, Subbarao (2003) framework predicated on the notion of "best features" of a well-designed public works programme is applied to determine whether features of the Ipelegeng programme are consistent with examples of international best practices. The core question is: Does IP's design conform to "best" practice principles in PWPs and whether the actual implementation of IP follows these principles? Subbarao (2003) explains that PWPs are those initiatives that typically provide short-term employment at low wages for 
unskilled and semiskilled people on labour intensive projects. He identifies five common reasons for the establishment of public works programmes. First, the programmes serve as insurance for the poor by providing income transfers at critical times. Second, they provide consumption smoothing for the poor when there is drought or crop failure. In that way, human tragedy through starvation is avoided. Third, when these programmes are well designed they provide useful infrastructure and services that have the potential to generate second round employment creation and economic growth. Fourth, that they can be targeted to specific regions in the country that are faced with high unemployment or poverty levels which makes these programmes a useful tool for both social and economic development. Fifth, their dependence on small scale private contractors has the potential to boost private sector growth.

Subbarao (2003) observed that when properly or well-designed, PWPs must exhibit the following features:

1) Self-selection: That the programme wage should be set such that only those who deserve and meet the programmes requirements apply and the well-off do not have the incentive to apply. The reason is that the alternative, rationing, has high administrative costs

2) Projects undertaken under such programmes should be of a high quality such that they add value to national assets and have the potential to generate second round effects on employment benefits.

3) Such projects should have high labour intensity in order for cost effectiveness to be achieved.

4) Targeting the poor should be central to the implementation of such programmes.

5) Public Works Programmes on their own do not have much impact on poverty and unemployment. Their impact is better felt when such programmes are linked to other economic empowerment programmes targeting the poor.

Subbarao's (2003) conceptual framework is appropriate in that it provides the basic principles of how a proper PWP should be designed, planned and implemented. Subbarao's approach is adopted here to provide a theoretically coherent guide to the current assessment on the contribution of IP towards poverty reduction in Botswana.

\section{Methodology}

An empirical nationwide study on the impact of IP on the lives of the beneficiaries was conducted in April to July of 2012. A qualitative multi-method research design was employed. Data were collected from a nationally representative sample comprising 23 research sites (cities, towns, and urban villages, rural and remote areas). Across the research sites, 95 in-depth interviews were conducted with key informants while 150 respondents participated in focus group discussions. This was followed by a detailed analysis of the data collected. The methods used were founded on the notion that IP beneficiaries have a unique knowledge base derived from their personal experiences, understandings and aspirations and therefore better suited to inform the study. Through this process, IP beneficiaries shared stories based on their experiences of Ipelegeng and its impact on their socio-economic wellbeing. Qualitative data obtained from fieldwork narratives were analysed and key results are presented and discussed in the next few paragraphs.

\section{Findings: What is Ipelegeng? Designs and Objectives}

Ipelegeng literally means to "carry your own weight". It denotes self-reliance with little or no dependency on the government. The concept was introduced in the hope of achieving the broad objectives of reducing poverty, creating employment opportunities, improving incomes and general quality of life for the poor and vulnerable groups in both rural and urban areas. IP typically provide short-term employment at low wages for the unskilled people through labour-intensive projects (NDP 10: 2009 - 2016; Gooch \& MacDonald 1981).

In terms of institutional design and implementation, the Ministry of Local Government and Rural Development through the Department of Local Government Development Planning and Community Development provide an oversight over the Ipelegeng programme. The programme, however, is implemented at local level by the Local Authorities (Districts and Urban Councils). In terms of eligibility criterion, anyone over 18 years of age may apply for an opportunity to work. However, applicants must have Omang (the national identity card) and be willing to work for the programme's low rate of pay. Ipelegeng was originally designed to provide relief from extreme poverty and is self-targeted. However, because of excess demand for the programme, the beneficiaries are expected to reapply for work every month to the Village Development Committee (VDC) in case of the rural areas or the Ward Development Committee (WDC) in case of cities and towns. VDCs and WDCs are responsible for recruitment of IP workers (IP Programme Guidelines, 2010). However, given the limited vacancies, those who were not recruited in the previous month are given priority. Since there is excess demand in most areas, a lottery 
system is employed to select the beneficiaries for purposes of rotation. This means that IP is rather limited in terms of coverage relative to the target group.

IP was introduced as a "flagship Programme" imposed by a directive issued from the Office of the President (Office of the President, Presidential Directive CAB 19 (A)/2008). The directive pronounced that IP unlike other "normal" government development programmes, would be constituency-based, as opposed to district-based. The effect of this directive has been that, funding and projects allocation are based on the size of the political constituency represented by a Member of Parliament (MP). Cabinet decides and allocates IP quotas for each monthly working cycle in each of Botswana's 57 Parliamentary Constituencies. Subsequently, the Ministry of Local Government and Rural Development allocates monthly quotas to respective Parliamentary Constituencies based on the size and share of the total population of Botswana which according to the 2011 national census stood at slightly over 2 million people (Statistics Botswana, 2011; Office of the President Presidential Directive CAB 19 (A)/2008).

Significantly, the Presidential Directive did not change the original design and implementation of IP but only expanded its mandate and structure with respect to resource allocation. Thus, the Directive lost an opportunity to re-design IP such that it is consistent with "best features" of a well-designed public works programme in the mold of that which was proposed by Subbaro, (2003). Consequently the result was a poorly designed Ipelegeng programme which has hitherto failed to produce the desired results. The critical question to ask is what impact has IP had to date? Has it managed to improve the lives of the intended beneficiaries in the short, medium and long-term? The findings from literature review, programme data as well as an evaluation of IP conducted in 2012 and recent anecdotes are instructive. The major findings of IP are presented in terms of achievements and implementation challenges. In terms of achievements, the following issues were identified: (i) funding of IP (ii) types of programmes implemented and their social and economic value and (iii) number of jobs created.

\subsection{Funding of IP}

Consistent with best practice examples of PWPs across the world, Botswana's Ipelegeng is fully state funded and has since its inception received generous funding from the Government. Expenditure on the IP programme has been increasing since the 2009/10 financial year. Expenditure increased from P219 million to P277 million during (2010/11); it rose to P301 million in 2011/12 before further increasing to P409 million during the 2012/13 financial year. IP was funded to the tune of P580 million during the 2014/15 financial year (Budget Speech, 2014/15). Noteworthy is that expenditure increased during the global financial crisis which started in 2008/09 when government revenues declined significantly. At the time of the study, Ipelegeng Programme continued to provide temporary relief to unemployed Batswana across the country. The approved budget for Ipelegeng Programme for the 2016/17 financial year stood at P612, 964,318, more than double the figure for 2011/12. Given its labour intensive nature, about $91 \%$ of the total Ipelegeng programme budget has been allocated for payment of the beneficiaries wages and the remainder is used for buying of equipment and related administrative costs (State of the Nation Address, 2016). Consequently, the programme has produced some positive results in regard to poverty reduction. This is a positive contribution towards the ordinary people's socio-economic well-being.

Evidence from programme data and the Review of Ipelegeng conducted in 2012, 2016 and 2017 identified some positive outcomes as reflected in the quote below from a respondent.

Ipelegeng is better than nothing. I have benefitted and I know other people who have worked for Ipelegeng in the past and some right now whose lives are better than was the case before they joined Ipelegeng. I am now able to buy mealie-meal, sugar and tea. I am able to take (items on) credit from the corner shop (kiosk) because they know I am working. I am able to buy my children school shoes and uniform. I am no longer a beggar, always asking from others but I can stand on my own feet now.

\subsection{Types of Programmes and their Social and Economic Value}

People who work on Ipelegeng across the country are engaged in a wide range of community and national development activities. Projects undertaken include environmental cleanliness, minor construction and maintenance of public facilities such as community shelters, maintenance of internal roads and drift fences, cleaning of streets, cutting of grass, and community policing. The programme also supports various initiatives such as Crime Prevention Volunteers and Special Constables under Botswana Police Service; Wildlife Volunteers, Waste Management Volunteers and Monuments custodians.

At present IP workers receive P567 (approximately US\$ 54) for six hours of work over a period of 20 or 22 days depending on the number of days in the particular month. Supervisors receive P651.00 (approximately US\$ 64) per month (Ministry of Local Government and Rural Development, 2018). The programme has also helped the 
Ministry of Environment, Wildlife, and Tourism with a cadre of volunteers called the Green Scorpions (environment voluntary police) who are hired for one year to protect the environment, in particular enforcing laws against indiscriminate disposal of litter and illegal mining of river sand.

Since 2012/13, beneficiaries are now supplied with a free meal at a cost of P5 per day to the government presumably to motivate them and provide nutrition. Significantly, the daily meals are supplied by small businesses drawn from the community and therefore the money stays in the local economy, and this helps create additional jobs and generate income for the local poor. This leads to increased cash circulation, creating rare employment opportunities for the poor leading to a general improvement in their quality of life (Swamy, 2003; Nthomang \& Tlagae, 2015).

\subsection{Jobs Created}

The major advantage of IP is that it has provided much needed relief from hunger and destitution to the poor, thus instilling a sense of dignity. Many Batswana who were jobless and idle are now engaged in Ipelegeng. Community leaders across the constituencies visited also underscored IP's achievements with respect to employment creation. One respondent spoke for many by stating thus:

People in this village do not have jobs at all. When IP recruit for available spaces, the Kgotla is filled to capacity. People of all ages come here in search for jobs. However, the majority are always women and the youth. This is clear testimony that Ipelegeng is very useful because it targets the poor and vulnerable and as such it should be continued and expanded because at the moment it can only absorb a few people each time.

Programme data revealed that Ipelegeng is supporting many public institutions by providing volunteers in such areas as crime prevention. Through these activities IP has created temporary employment opportunities for many across the country. For example, in May 2013, a total of 56,274 people were working on the programme, and these consisted 39,998 women ( 71 percent) and 16,276 men ( 29 percent). Of the total, 18,034 (32 percent) were working in urban areas while the rest were in rural areas. Further, out of the total of 56,274 beneficiaries, 6,590 were crime prevention volunteers and 504 special constables (police assistants). As of July 2016, a total of 63,688 people were engaged in IP suggesting the numbers continue to increase fast (Final Report on the Review of Ipelegeng, 2012).

\subsection{Implementation Challenges}

Despite these positive results, programme evidence based on the various reviews, anecdotes and observations alluded to earlier suggests that over the years IP has encountered a number of challenges that have negatively impacted on its core objective, namely poverty reduction. An interview with key informants revealed that in its present form, IP is fraught with operational difficulties, with activities fragmented, disjointed and scattered all across a number of government ministries and departments and local authorities. The following challenges were identified; (i) IP poor design and lack of comprehensive programme information (ii) IP lack clear objectives (iii) IP limited coverage and (iv) the lottery system excludes the deserving poor.

A key informant noted with respect to the above:

Fragmentation makes it virtually impossible for the relevant ministry to monitor and coordinate IP activities effectively. Failure of some Ipelegeng projects is because there is lack of inter-sectoral collaboration or a holistic approach to delivery of IP activities. As a result you find duplication of activities by various departments because the right hand does not know what the left hand is doing. In my district lack of coordination has compromised effectiveness of what would otherwise have been a good Government initiative. It has led to inefficiency in allocation of scarce human and physical resources.

Another key informant was emphatic that:

Ipelegeng is poorly designed and implemented. The architects of IP did not learn from the previous mistakes in the implementation of Ipelegeng. Mistakes such as low labor productivity, lack of inputs and political interference (expediency) have not been addressed. For example, in my district, one of the fundamental flaws of IP is that it did not specifically target the poorest of the poor, has limited coverage, is not efficient (cost-effective) and has failed to engage in programmes of high quality.

The challenges identified above underscore the importance of proper project design and implementation and that failure to adhere to set standards often results in under-performance. There is a tendency to introduce flagship programmes in haste to appease the electorate. Often times there is an attempt to try to achieve as much as possible, quickly and in the process the critical aspects of planning such as institutional and management capacities needed 
to carry-out the programme are compromised. The resultant mistakes are inevitable and this has caused the apparent failure of the IP.

\subsubsection{IP poor Design and Lack of Comprehensive Programme Information}

Furthermore, FGDs identified some of the factors that undermine the contribution of IP towards poverty reduction. The quote below from a participant in a FGD, encapsulates the essence of this observation, thus:

We are concerned about IP failure to improve quality of life of its beneficiaries who have remained in a perpetual state of poverty despite IP implementation. There is no or very little qualitative improvement in lives of many IP beneficiaries. People work for Ipelegeng but there is very little to show. Many people's lives have not improved ... we are still very poor.

The above-expressed sentiments suggest the prevalence of a feeling that the implementation of the Ipelegeng programme has not been successful against a backdrop of massive financial support from the Government of Botswana. This can be attributed to the flawed design, methodology and approach of IP towards poverty reduction.

Another participant in a focus group discussion ad speaking on behalf of fellow participants, observed:

I am concerned we never challenge IP to deliver results and generally no attention is paid to costs. In fact there are concerns that IP was not designed to be results-based. The present situation is that IP beneficiaries are paid for time spent at work and not for work done. As a result a lot of funds get wasted and cannot be accounted for. The "it is better than nothing" mentality has killed the zeal to work hard and deliver project outcomes that make a difference in people's lives at a minimum cost. Nobody seems to be concerned about value for money or return on investment.

One of the FGD participants, expressing a sentiment shared by his group members noted with concern:

We are concerned that IP architects failed to design the programme in a manner that enhances the complementarity between its projects and other economic activities. For example, one current problem is that IP competes with agriculture for labour. This is because IP activities, though short term are carried out throughout the year and the wages are higher than those in the agricultural sector and thus creating a disincentive for the beneficiaries to engage in agriculture. Proper time scheduling for Ipelegeng should make it possible for labour to be shared between economic activities and sectors.

To this end, one FGD participant, speaking on behalf of fellow participants, expressed the need to:

Ensure that Ipelegeng puts more emphasis on the need for participants to graduate from IP into more productive and sustainable poverty eradication programmes in agriculture such as the Integrated Support Programme for Arable Agricultural Development (ISPAAD) which has so far been overlooked. We believe that this is a mistake that should not have occurred because IP on its own does not have much impact in terms of reducing poverty and creating sustainable jobs. The impact of IP can only be felt when its activities are linked to other economic empowerment programmes targeting the poor.

The observations made by FGDs above were confirmed by key informants who expressed concern over poor supervision and lack of coordination by those responsible for IP implementation. One of the key informants spoke for many when he pointed out that:

Since IP is reliant on government machinery to deliver on its mandate, implementing Government ministries, departments and local authorities should coordinate their efforts and pull resources together to deliver as one with a view to ensure that the objectives of IP are met. Unfortunately, in practice, departments or officers who were supposed to be involved were either not consulted or had not shown interest in the programme. There are many administrative challenges that hinder effective implementation of IP in all the constituencies. These are; top-down approach, which has come to characterize the relationship between the Ministry of Local Government and Rural Development and Local Authorities, charged with the implementation of IP.

In-depth interviews conducted with IP District Coordinators revealed that their ability to contribute to the rationale and design of some aspects of Ipelegeng was limited because they were not allowed to make decisions on the ground to ensure effective delivery of IP projects. One of them asserted that:

We always have to wait for decisions and/or directives coming from the Ministry Headquarters or Office of the President. They do not allow us to make decisions yet it is us who deal with IP implementation issues and challenges on the ground on a daily basis. It is important they talk to us and listen to what we have to say. This will improve delivery of IP services to the beneficiaries. 
IP coordinators also expressed concern about lack of comprehensive programme information and the absence of inter-departmental synergy and coordination for effective implementing of IP. They opined that this void had kept Local Authorities out of the loop, and as a result numerous mistakes and blunders had been made due to poor coordination and understanding of IP objectives. To this end, one IP Coordinator noted that:

The current set-up releases other departments from direct institutional responsibility for reduction and prevention of poverty and limits the extent to which various departments with a poverty reduction and poverty prevention mandate can work in concert to reduce poverty. In fact, this is a case where the right hand does not know what the left hand is doing and this has led to duplication of efforts and poor implementation.

\subsubsection{IP Lack Clear Objectives}

Other challenges gleaned from the field related to lack of clear objectives, a negative attitude towards the programme, inadequate staffing, and weak institutional arrangements. Consequently, limited progress had been made towards the realisation of IP objectives because of poor supervision and coordination. This had led to wastage of resources.

Another challenge noted by the respondents, was eloquently articulated by one of them thus:

Ipelegeng has not provided skills to the low and unskilled workers. This is a major problem because the majority of people do not have survival skills and as a result the majority have become very dependent on IP for survival. This means that IP has failed to build capacity of the poor for self-reliance and sustainable livelihood but instead the beneficiaries had become more dependent on the Government.

The fact that the majority of IP beneficiaries do not seem keen to graduate from Ipelegeng is clear testimony that the programme has not imparted survival skills, suggesting it has had very little if any, impact on the lives of the intended beneficiaries.

\subsubsection{IP Limited Coverage}

There is near consensus that the IP programme's coverage has been quite limited given that it is based on a limited quota system. The programme has over the years covered between 50, $000-56,000$ people (per month) within the 18-64 age target group, against an estimated 360,000 or 84000 families living in extreme poverty (BCWIS 2009/10; WB \& BIDPA, 2013; Statistics Botswana, 2015/16). This is quite low given the large numbers of people who live in absolute poverty, as well as the number of low skilled people who are unemployed throughout the country (See Statistics Botswana, 2013; 2015/16). Limited coverage by IP has resulted in excessive demand for the programme, which has meant that a lottery is needed in most constituencies to select the beneficiaries.

\subsubsection{The Lottery System Exclude the Deserving Poor}

Although unavoidable given large numbers of unemployed poor, the lottery system has excluded many deserving poor people who are the primary beneficiaries of IP. The World Bank Social Protection Assessment Report (2013) has decried low coverage and poor targeting of the IP programme. According to their estimates, IP covers only 3 percent of the intended beneficiaries. The situation is made worse by a lottery approach which effectively leave some of the deserving poor out of Ipelegeng on account of failure to win a lottery on a continuous basis (BIDPA \& World Bank, 2013; Holm \& Morgan, 1985).

From the foregoing discussion, it is evident that IP is riddled with many challenges that undermine its effectiveness. In particular, what appear to be the political pressure to deliver IP to the immediate gratification of the beneficiaries has overpowered the need to properly plan and execute Ipelegeng systematically and run it more professionally. The prevailing situation is characterized by: (i) poor design and a general absence of in-built monitoring and evaluation procedures in all IP projects, and (ii) the absence of detailed implementation plans that identify actions, targets, establish performance indicators as well as roles and responsibilities for effective implementation.

In light of the challenges presented above, the critical question to ask: Is Ipelegeng the answer to poverty reduction in Botswana? Can IP provide solutions to the challenges facing the poor? Clearly, the challenges noted above are capable of undermining IP's efforts to deliver effectively on its broader mandate of poverty reduction and general improvement in the quality of life of poor and vulnerable people in Botswana. Taken together, IP poor design and methodological flaws evidently conspired to undermine the effective contribution of IP towards poverty reduction. The design of any given development programme serves as a foundation to build upon. A weak foundation often leads to the collapse of a programme. Programme designers, policy makers and other stakeholders should therefore pay undivided attention to the design stage of IP in order to make IP more effective. As currently designed and implemented, IP is not effective, and therefore needs to be re-designed. IP's limited impact can justifiably be 
attributed to its failure to conform to best practice features of PWPs adopted throughout the world. Evidently, IP did not have in place a plan on how to cater for the pool of potential poor people on the "edge" of poverty in the event that they had not been absorbed into its activities because of the enormously large number of people on the waiting list being rotated.

\section{Discussions and Analysis}

The reasons that motivated the introduction of Ipelegeng are clear. The programme was introduced for purposes of reducing poverty, creation of employment opportunities for the rural and urban poor with a view to improving their quality of life. These objectives remain valid today (cf Government of Botswana - National Development Plans, 1965-2016). The Government of Botswana has over the years made concerted efforts to deliver on the objectives of Ipelegeng. For example, IP is fully funded by the Government, it is a labour-based programme, it targets the unskilled and semi-skilled poor, it is implemented all year round, is constituency based (suggesting it has wider coverage and reach). This notwithstanding, IP has made only modest achievements towards poverty reduction. Those involved have benefited little from IP in terms of temporary relief from poverty and unemployment (Siphambe, 2003; Seleka et.al., 2007). Under the circumstances, there is need to re-design and strengthen IP so that it is able to better deliver on its original mandate of poverty reduction through employment creation. The focus should be on sustainability through creation of more jobs that are permanent and imparting of skills that will empower its beneficiaries so that they become more self-reliant Economic emancipation will enable IP beneficiaries to graduate from Ipelegeng into other Government supported economic empowerment projects targeting the poor such as the ISPAAD and Alternative Packages (Gender and Development Programmes).

However, several reviews and evaluations of the IP programme indicate that it was poorly designed and lacks an in-build monitoring and evaluation framework with clearly defined targets and indicators meant to track progress towards achievements of set objectives. As a result it is difficult to assess the extent to which IP is able to effectively deliver on its objectives. Available evidence suggests that IP successes have been far outweighed by its failures (cf Oxford Food Studies Group (FSG) 1990; BIDPA and UNICEF, 2012). Thus, IP's contribution to poverty reduction through employment creation has hitherto been very minimal. Instead of improving the socio-economic wellbeing of the poor, IP beneficiaries have remained in a perpetual state of poverty. Many have reportedly been turned into welfare clients, dependent on the state. Research evidence points to several challenges that account for this unfortunate state of affairs. The identified challenges include; (i) IP's flawed design, methodology and approach (ii) lack of mechanisms for proper supervision and coordination, and (iii) limited coverage and poor targeting. These are briefly discussed in the next few paragraphs.

\subsection{IP Flawed Design, Methodology and Approach}

The argument that runs down the gamut of the paper is that IP is poorly designed and as such had failed to conform to international best practice examples of PWPs and therefore unable to deliver effectively on its overarching mandate of poverty reduction, provision of temporary employment and improving the incomes of the target population in comparison to other similar PWPs elsewhere in the world, such as in South Africa, Ethiopia, India and Latin America.

A critical assessment of the IP's contribution towards poverty reduction, based on empirical evidence contained in the Final Report on the Review of Ipelegeng of 2012 which revealed a number of methodological and design problems, including:

- Higher wage rate offered by Ipelegeng than the prevailing market rate for low skilled workers (e.g. agriculture) had resulted in the programme becoming quite attractive to the non-poor, who have made it a point to wrestle opportunities away from the poor who are supposed to be the target of the programme. This is a design problem that undermines the spirit of self-selection. IP was primarily intended to benefit 84,000 extremely poor households (See BCWIS, 2009/10; Statistics Botswana, 2013), but some of the slots have been taken by people who are not necessarily poor and should not be on the programme in the first place.

- IP's coverage has been very limited relative to the target group. The programme uses quota and rotational approaches, and as such, can only target a limited number of people in each cycle of recruitment. This undermines one of the internationally acclaimed best attributes of PWPs, relating to the promotion of high labour intensity projects in order to achieve cost effectiveness.

- The architects of IP failed to design the programme in a manner that enhances the complementarity between its projects and other economic activities. For example, one current problem is that IP competes with agriculture for labour. This is because IP wages tended to be higher than those in the agricultural sector creating a disincentive for beneficiaries to engage in agriculture. 
- The need for participants to graduate from IP into more productive and sustainable poverty eradication programmes such as the Integrated Support Programme for Arable Agriculture (ISPAAD) was apparently overlooked. It is common course that PWPs on their own do not have much impact on poverty reduction and unemployment. Their impact can be better felt if they are linked to other economic empowerment programmes targeting the poor.

\subsection{Supervision and Coordination Mechanisms}

Numerous reviews of PWPs around the world have underscored the importance of supervision and coordination in the implementation of PWPs (Subbarao, 1999; 2003:14). Expectations are that since IP is reliant on Government machinery to deliver on its mandate, then implementing government ministries, departments and local authorities ought to coordinate their efforts and pull resources to ensure that the objectives of IP are met. Empirical evidence (cf BIDPA and UNICEF, 2012; Gooch \& MacDonald 1981; Government of Botswana 2002) however, suggests that departments or officers were either not consulted or had not shown interest in the programme. IP implementers at local level identified a number of administrative challenges that hinder effective implementation of IP, including: (i) adoption of a top-down approach, which has tended to characterize the relationship between the Ministry of Local Government and Rural Development and Local Authorities charged with the responsibility of implementation of the IP. In-depth interviews conducted with IP District Coordinators revealed that their ability to contribute to the rationale and design of some aspects of Ipelegeng was limited as they were given no room to make decisions on the ground to ensure effective delivery of IP projects. They always had to wait for directives from the Ministry Headquarters or Office of the President.

\subsection{Poor Targeting}

A properly designed PWP should ensure that the intended beneficiaries, i.e. the poor are deliberately identified and targeted (Ipelegeng Guidelines, 2010; BIDPA, (2010). Proper targeting would ensure that IP projects are executed in areas that are close to where the poor people live, and this would facilitate easier access. Projects so identified should also compliment rather than compete with the beneficiary's time for other economic activities. This helps maximise utility of the projects by the poor (Sabbarao, 1997). The reality in the case of Botswana is that because of poor targeting, IP has tended to be quite attractive to the better-off or the undeserving poor contrary to its original mandate.

In order to address the above gaps, Phillip (2004) has suggested best practice to be emulated, including:

i) Consistent political support and a multi-year programme

ii) Resources and adequate time allocated to planning the programme and developing the capacity to implement it

iii) Planning of programme to ensure that the pace of implementation is linked to the quality and outcomes of the programme. High priority be given to effective systems of monitoring and evaluation

Lessons learned from Asia, Latin America and some African countries do underscore the need to conform to the "best features" approach in the design of PWPs as advocated by Subbarao (2003). To realise this goal, it will be important to consider the following: (i) increasing scope of coverage to improve self-targeting (ii) increasing number of months of employment (iii) increase number of places (iv) ensuring programme budget allocation is proportional to regional poverty levels (v) improve on the quality and utility of the public works initiative (vi) ensuring a clear focus on skills development for sustainable livelihood, and (vi) provide a robust legal framework for the programme.

Consistent with the proposals made above, Phillip (2004) identified a number of mistakes to avoid during the design and implementation stages of PWPs, and these include the following:

i) Concise and a clearly defined definition of the target group,

ii) Coordination and harmonization flaws,

iii) Aiming to achieve too much too quickly (overloading the programme). This can lead to sacrificing some of the objectives of the PWPs, such as providing quality services, or using labour intensive methods.

iv) Not allowing time to plan properly and build the required institutional and management capacity for effective and efficient implementation.

v) Lack of consistent political support. 


\section{Conclusion and Way Forward}

The paper sought to assess the contribution of IP towards poverty reduction in Botswana. Factors that promote and hinder effective contribution of IP towards poverty reduction were identified and examined. It emerged that successes and failures of the IP lay in its design and implementation. While the programme has recorded some successes, its greatest challenge is in poor design and its failure to conform to international best practice principles of PWPs. Research evidence suggests that for public works programmes to make a positive impact on poverty reduction, they should be designed such that they conform to and incorporate all the best features of a well-designed PWPs (see Subbarao, 2003; Philips, 2004; Andrews \& Manamela 1991; Holmes \& Jones 2011), including self-selection, targeting the 'deserving' poor and that such programmes should have high labour intensity. Clearly IP has not conformed to the set criteria and hence its ineffectiveness in reducing poverty. Programme data revealed that Ipelegeng projects are not cost-effective as they do not yield meaningful returns on investment. That IP is relevant is not in dispute, what is at issue is IP's inability to produce results and the very limited impact it has had on the quality of beneficiary's lives. Clearly it has not helped reduce poverty but instead has caused many of its beneficiaries to overly dependent on the state. It is clear that the key to successful implementation of IP lies in changing the programme's philosophical orientation, design, implementation methodologies and approaches. There is need to strengthen institutional structures and coordination mechanisms for effective delivery of IP projects. It is therefore not unreasonable to conclude that in its current formant, Ipelegeng cannot be an answer to poverty reduction in Botswana as it has failed to provide solutions to the problems facing poor people in Botswana.

\section{References}

Andrews A. P., \& Manamela N. J. (1991). Operationalizing a country-wide Labour Intensive Public Works Programme in Rural Botswana. Develop-metrics (Pty) Ltd.

BIDPA, (2010). Review of the National Strategy for Poverty Reduction: Social Protection for Poverty and Vulnerability Reduction. Unpublished Consultancy Report. Gaborone: Botswana Institute for Development Policy Analysis (BIDPA).

Botswana Institute for Development Policy Analysis (BIDPA) \& World Bank (WB) (2013). Social Protection Assessment Report. Gaborone: BIDPA \& WB.

Botswana Institute for Development Policy Analysis (BIDPA) and UNICEF (2012). Final Report for the Review of Ipelegeng Programme. Gaborone: BIDPA \& UNICEF.

del Nnino, C., Subbarao, K., \& Milazzo, A. (2009). How to make Public Works Work: Areview of the Experiences. SP Discussion Paper No. 0905. Washington DC: World Bank.

Gobotswang, K. S. M. (2004). Poverty Alleviation Strategies in Botswana: The Case of Labour-Intensive Public Works Programme (LIPWP). Botswana Notes and Records, 36, 27-36.

Gooch, T., \& MacDonald, J. (1981). Evaluation of Labour Related Projects in Drought Relief and Development. Ministry of Finance and development Planning. Gaborone Botswana

Government of Botswana. (1965 -2016). National Development Plans. Gaborone: Government Printer.

Government of Botswana. (2002). Revised National Policy on Rural Development. Gaborone: Government PrinterGovernment of Botswana (2008) Presidential Directive CAB 19(A)/2008.

Holm, J. D., \& Morgan, R. G. (1985). Coping with Drought in Botswana: An African Success. Journal of Modern African Studies, 23(3), 463-482. https://doi.org/10.1017/S0022278X00057189

Holmes, R., \& Jones, N. (2011) Public works programmes in developing countries: Reducing gendered disparities in economic opportunities. Paper prepared for the International Conference on Social Cohesion and Development, 20 - 21 January 2011, Paris, France.

Lal, R., Miller, S., Lieuw-Kie-Song, M., \& Kostzer, D. (2010). Public Works and Employment Programmes: Towards a Long-Term Development Approach. International Policy Centre for Inclusive Growth (IPC - IG) Poverty Practice, Bureau for Development Policy, UNDP, Brasilia, DF - Brazil.

McCord, A. (2000). An Overview of the Performance and Potential of Public Works Programme in South Africa. SALDRU/CSS Working paper No. 49. University of Cape Town.

McCord, A. (2004) Policy expectations and programme reality: The poverty reduction and labour market impact of two public works programmes in South Africa. ESAU working paper 8. London: Overseas Development Institute (ODI). 
Ministry of Finance and Development Planning. Budget Speeches 2009/10; 2010/11; 2011/12; 2012/13; 2013/14; 2014/15. Gaborone, Botswana: Government Printer.

Ministry of Finance and Development Planning. (n. d.). National Development Plan 10 (2009 - 2016). Gaborone, Botswana: Government Printer.

Ministry of Local Government. (1982). Evaluation of the Drought Relief and Recovery Programme, (1982-90). Gaborone: Government Printer.

Ministry of Local Government. (1996). Review of Labour Based Public Works (1996). Gaborone: Government Printer.

Ministry of Local Government and Rural Development. (2010). Ipelegeng Guidelines. Gaborone: Government Printer.

Ministry of Local Government and Rural Development and UNICEF. (2012). Final Report on the review of Ipelegeng. Gaborone: Government Printer.

Ministry of Presidential Affairs and Public Administration. (2017). Botswana National Vision - Vision 2036. Gaborone: Government Printer.

Nthomang, K., \& Tlagae, D. (2015). Empowering women and families through self-help groups: The Botswana Experience. In Lekoko, R. N. (Ed.), Cases on grassroot Campaigns for Community Empowerment and Social Change. Hershey PA. IGI. https://doi.org/10.4018/978-1-4666-8568-0.ch001

Nthomang, K. (2012) Basic Social Services and Poverty reduction In Botswana: In Selolwane,O (Ed.), Poverty Reduction and Changing Policy Regimes in Botswana. United Nations Institute for Social Development (UNRISD) - Lndon: Palgrave MacMillan. https://doi.org/10.1057/9781137270177_5

Office of the President. (2008). Presidential directive CAB 19 (A) 2008. Gaborone: Office of the President.

Oxford Food Studies Group (FSG). (1990). Report on the Evaluation of the Drought Relief and Recovery Programme, 1982-1990 Volume 1 Main Conclusions and recommendations. University of Oxford

Phillips, S. (2004, October 29). The Expanded Public Works Programme (EPWP). Presentation to the UNDP, HSRC \& DBSA Conference on Overcoming Under-development in South Africa's Second Economy, Pretoria, South Africa.

Samson, M., van Niekerk, I., \& Mac Quene, K. (2006). Designing and Implementing Social Transfer Programmes. Economic Policy Research Institute (EPRI). Capetown, South Africa.

Seleka, B. T., Siphambem H., Ntseane Mbere, N., Kerapeletswe, C., \& Sharp, C. (2007). Social Safety Nets in Botswana. Administration, Targeting and Sustainability. Gaborone: Botswana Institute for Development Policy Analysis (BIDPA), Lentswe la Lesedi.

Siphambe, H. K. (2003). Dimensions and Measures to Reduce Poverty in Botswana. Pula: Botswana Journal of African Studies 17(2), 19-25.

State of the Nation Address by Lt. General Dr. Seretse Ian Khama. (2016). Gaborone: Government Printer.

Statistics Botswana. (2009/10). Botswana Core Welfare Indicator Survey (BCWIS). Gaborone: Statistics Botswana.

Statistics Botswana. (2011). National Population and Housing Census. Gaborone: Statistics Botswana.

Statistics Botswana. (2013). Botswana Core Welfare Indicator Survey, 2009/10. Gaborone: Statistics Botswana

Statistics Botswana. (2015/16). Botswana Multi-Topic Household survey (BMTHS) poverty stats brief, 2015/16. Gaborone: Statistics Botswana.

Subbarao, K. (1997). Public Works as an anti-poverty program: An overview of cross country experience. Paper presented at ASSA Annual Meetings. https://doi.org/10.2307/1244171

Subbarao, K. (1999). Financial Crises and Safety Nets: Old and the New Poor in Korea. World Bank, Washington, D.C. Processed.

Subbarao, K. (2003). Systemic Shocks and Social Protection: The role and effectiveness of public works. Social Protection Discussion Paper 0302. Washington DC, World Bank.

Swamy, G. (2003). Gender Dimension of Public Employment Schemes. SP discussion paper. Washington DC: World Bank. 
Teklu, T. (1995). Labor-Intensive Public Works: The Experience of Botswana and Tanzania', Chapter 6 in J. von Braun (ed.), Employment for Poverty Reduction and Food Security, Washington D.C.: IFPRI. Retrieved from http://www.ifpri.org/pubs/books/vonBraun95/vonBraun95ch06.pdf

Teklu, T., \& Asefa, S. (1999). Who participates in Labour-Intensive Public Works in Sub-Saharan Africa? Evidence from Rural Botswana and Kenya, World Development, 27(2), 431-438. https://doi.org/10.1016/S0305-750X(98)00137-5

United Nations Development Programme. (2002). A Review of Anti-Poverty Initiatives in Botswana: Lessons for a National Poverty Reduction Strategy. Government of Botswana

World Bank \& Botswana Institute for Development Policy Analysis. (2013). Botswana Social Protection Assessment Report. Gaborone: World Bank \& BIDPA.

World Bank. (2008). Ethiopia Agriculture and Rural Development Public Expenditure Review 1997/98 2005/06. World Bank: DC.

\section{Copyrights}

Copyright for this article is retained by the author(s), with first publication rights granted to the journal.

This is an open-access article distributed under the terms and conditions of the Creative Commons Attribution license (http://creativecommons.org/licenses/by/4.0/). 